\title{
Library User Education and Student's Utilization of Library Resources in University of Port Harcourt, Rivers State, Nigeria
}

\author{
Dr. Boma Torukwein.David-West, CLN \\ Department of information and library science, University of Port Harcourt, Rivers State, Nigeria
}

\begin{abstract}
The study examined library user education and student's library utilization in University of Port Harcourt, Rivers State, Nigeria. Three research questions and 3 hypotheses were answered and tested in the study respectively. The design of the study was the descriptive survey design. The population of the study consisted of undergraduates students who are in Department of Fine and Applied Arts from year 1-4. The census sampling technique was used because the study used the whole population. The instrument of the study was validated item instrument titled (ILUESLUQ) designed by the researcher in the modified 4-point Likert Scale type with reliability of 0.82 obtained using the Cronbach Alpha Method. Mean and standard deviation were used in answering the research questions while z-test was used in testing the hypotheses at 0.05 level of significance. The findings revealed that there is a significant difference between library user education and student's utilization of library by faculty of humanities, University of Port Harcourt. It was concluded that librarians should be very proactive when it comes to user education in order to promote library usage. It was recommended among others that GES 100 library use course should be given prominence in the University. Students should also be graded in practical usage not just in examination, in order to assess their performance on the usage of library facilities and resources so as to attain coveted educational goals.
\end{abstract}

Keywords: Library, user, education, students, utilization, University.

DOI: $10.7176 / \mathrm{IKM} / 10-1-02$

Publication date: January $31^{\text {st }} 2020$

\section{Introduction}

The role of library is to support teaching, learning and research in the university. The library is a very vital component of the university and none of these roles can be actualized without effective user education programme aimed at creating awareness on how to make use of the library services and resources effectively. Library user education is an important part of an academic library's service, as it guides both students and staff to become better informed and effective library users. It also enables them to make use of the best library resources available. If library services and resources are not fully utilized it is good as not having a library.

Uwakwe, Onyeneke and Njoku (2016) states that user education is a process whereby potential users are made to learn how to make efficient and effective use of library resources through the acquisition of knowledge skills in identification, location, retrieval and exploitation of information. User education inform and influence user's opinion and attitudes towards library usage and also inspire their quest for knowledge which is essential for the advancement of individuals and societies (Qianxiu, Patrick and Itsumura (2016). The library user education determines the dimension of library use.

The library user education is expected to have various positive effects on student's learning research practice and for independent life-long learning, it teaches students to make use of library resources without assistance from library staff. Library user education programmes normally encourages a number of aspects of library services such as library tours, library orientation and also the teaching of general studies (GES 100). Bembura (2015) indicated that improper guidance and lack of professional, inadequate collections, as well as insufficient networked computers have been the main draw backs for student's exploring the library resources.

In other words for library assessment to be valid, the library users must be involved in evaluating the library services they are receiving. This will help the library management to know if it is actually meeting up with its set goals and objectives. The major problems faced by many academic libraries is how to organize user education more effectively to cater for the students diverse learning needs and expectations. The quality of user education determines the rate of use of a library. This also actualizes the sustainable optional user satisfaction. A poorly package user education may account for low rate of use of library resources and services. This study is designed with the aim of examining user education and its influence on library usage.

\section{Statement of Problem}

Some researchers suggest that inquiry based learning should be made an integral part of any student's learning at the university level. It is observed that students most times come in with their text books and notes to read in the library. They don't actually make use of the library resources. Some students that try to use the resources depend on the library staff to locate information resources. This has however caused underutilization of library resources. It has also made the student's not to be skilful and effective user of library. Despite the effort of 
library management introducing library user education, the problem still persist. This is why the researcher decided to carry out this study to find out why? Library resources are underutilized and also possibly proffer solution.

\section{Objectives of the Study}

1. To ascertain library tour and student's utilization of .library resources in University of Port Harcourt.

2. To determine GES 100 and student,s utilization of library resources in University of Port Harcourt.

3. To find out how library orientation enhances student.s utiliuzation of library resources in University of Port Harcourt.

\section{Research Questions}

1. How does library tour enhance student's utilization library resources in University of Port Harcourt?

2. How does the course GES 100 enhance student's utiliation of library resources in University of Port Harcourt?

3. How does library orientation enhance student's utilization of library resources in University of Port Harcourt?

\section{Hypotheses}

Ho1: There is no significant difference between library tour and student's utilization. of library resources in University of Port Harcourt

Ho2: There is no significant difference between library use course (GES 100) and student's utilization of library resources in University of Port Harcourt.

Ho3: There is no significant difference between library orientation and student's utilization. of library resources in University of Port Harcourt.ss

\section{Literature Review}

The essence of library user education is to equip library users with enough knowledge and skills on the use of library resources effectively and efficiently( Ogunnodede and Emeahara 2010). They also observed that the resources in the library are so complex that an average library user cannot comprehend them. Also Maxwell, Richard and Cunning (2014) concluded that libraries can allocate their limited resources to be more relevant to current student's needs, specifically in the areas of staff professionalism, customer services, modern equipment and facilities while strategically expanding their e-campus and online holdings. As a result, it will improve in the end, and students are more likely to use the library services.

Kiilu and Otike (2016) found that the leading reasons for infrequent non-use of library resources include the lack of awareness, perceived lack of relevance, lack of time, long distance to go to reach the library, lack of skills in the use of electronic resources, access to the internet from home, as well as borrowing from other libraries. The scholar further stated that library orientation is therefore necessary for effective use of library that facilitates information gathering and utilization aimed at student's effective academic performance. Discussing on various methods of impacting or teaching the skills on the use of library Maduako (2013) explained that, methods of teaching user education consists of all types of activities designed to teach users about library facilities and search strategies in order to equip students with basic skills to enable them to make optimal, effective, efficient and independent use of information resources and service available in the library.

Similarly, Joseph(2005) identifies the following problems of user education, overdependence, one day of orientation programme in Nigerian universities. Also Obasuji and Idiodi (2015) indicates that student's perceived the library to be of great value to their education and it had an impact on their academic pursuits, studies, and academic performance.

Bem-bura (2015) conducted a survey to find the student perception of library orientation programme in Benue State University of Makurdi. Results of the study showed that considering the immersed benefits of the orientation programme cannot afford to ignore the importance of carrying out the programme as the study believed that students benefited from the programme to a very high extent.

$\mathrm{Li}(2013)$ sees it as education activity of library and other information institution to develop and improve the ability of users to use the information of literature. This has to do with actively cultivating user's interest as a major task of library user education. Hsu, Cumminer and Wang (2014) conducted a questionnaire survey in a university located in the Midwest region USA. They concluded that libraries can allocate their limited resources to be more relevant to the current student's population, especially in the area of staff professionalism, customer services, modern equipment and facilities while strategically expanding their campus and online holdings. This will result in service quality for students which will improve the utilization of library services.

Esse and Ugwumba (2014) are of the opinion that there cannot be a connection between user and materials 
or tools without proper education given to users who may not have prior knowledge or idea on the use of such materials. Library user education is an indispensable instrument for effective use of library resources. The benefits of user education is such that it cannot be over emphasized following a study that the disposition of students in university library in south western Nigeria was totally positive with $100 \%$ respondents indicating that library user education course had enhanced their knowledge of the library and its functions.

Moreso kanazawa (2016) stated the main issues in Japanese academic libraries need to have a variety of educational contents, as well as execute more advance library user education far beyond library orientation. In other words, all the literature revealed that library user education enhances the effectiveness of any library using the resources and services.

\section{Methodology}

Descriptive survey design was adopted for this study. The population of the study is made up of 181 undergraduate students in the Department of Fine Arts and Design in the Faculty of Humanities. The whole population was selected as sample using census sampling technique. The main instrument for data collection was questionnaire (LUESLUQ). The instrument was validated by experts in the department of guidance and counseling. 181 questionnaire was given out and one hundred and seventy (170) was retrieved which represents 93.9\% return rate. Mean (x) and standard deviation was used to answer the research question while the $\mathrm{z}$ test was used to test the hypothesis at 0.05 significant level.

The scope of this study will not go beyond students in the Faculty of Humanities in the Department of Library and Information Science, University of Port Harcourt, Rivers State, Nigeria. It restricts itself to the variables identified in the purpose of the study, research questions and hypotheses.

Library users' education (LUE) students Library Utilization

Table 1: Mean scores of respondents on the impact of library tour on student's library utilization.

\begin{tabular}{|c|c|c|c|c|c|c|c|}
\hline \multirow[t]{2}{*}{ Questionnaire Item } & \multicolumn{2}{|l|}{$\mathrm{LT}$} & \multicolumn{2}{|l|}{ SLU } & \multirow{2}{*}{$\begin{array}{l}\text { Mean } \\
\text { Set }\end{array}$} & \multirow{2}{*}{$\begin{array}{l}\text { Rank } \\
\text { Order }\end{array}$} & \multirow[t]{2}{*}{ Decision } \\
\hline & $\mathrm{X}$ & St.D & $\mathrm{X}$ & St. D & & & \\
\hline $\begin{array}{l}\text { Library tour is helpful in terms of building } \\
\text { a positive image about the university } \\
\text { library and its services. }\end{array}$ & 2.88 & 0.55 & 2.70 & 0.52 & 2.79 & $2^{\text {nd }}$ & Agreed \\
\hline $\begin{array}{l}\text { The tour is very useful and relevant to my } \\
\text { current research }\end{array}$ & 2.65 & 0.41 & 2.75 & 0.53 & 2.7 & $1^{\text {st }}$ & Agreed \\
\hline The library tour is boring to one & 2.47 & 0.40 & 2.64 & 0.42 & 2.56 & $3^{\text {rd }}$ & Agreed \\
\hline $\begin{array}{l}\text { I do not know when the library tour is } \\
\text { conducted }\end{array}$ & 2.76 & 0.54 & 2.59 & 0.45 & 2.68 & $4^{\text {th }}$ & Agreed \\
\hline Aggregate Mean Score & 2.69 & 0.48 & 2.67 & 0.48 & 2.96 & & Agreed \\
\hline
\end{tabular}

\section{Key: Library Tour(LT) Students Library Utilization (STU)}

Data on table 1 describe the mean scores and standard deviation of Library Tour (LT) and Student's Library Utilization (SLU). The respondents agreed on all the items in the table with high mean scores greater than the mean criterion of 2.50 following the rank order from $1^{\text {st }}$ to $4^{\text {th }}$. The aggregate mean score of 2.98 shows that the ways library tour enhances student's library utilization in the faculty of humanities in University of Port Harcourt include: it builds positive image about the university library and its services, it is relevant to research, tour is not boring to the user. Tour is made known to users, which enhances effective teaching and learning to take place at the level of student's library utilization geared towards the attainment of optional education goals.

Research Question 2: How does the course "GES 100" enhance students' library utilization?

Table 2: Mean scores of respondents on the impact of the course "Library Use" GES 100 on students Library Utilization.

\begin{tabular}{|c|c|c|c|c|c|c|c|}
\hline \multirow[t]{2}{*}{ Questionnaire Item } & \multicolumn{2}{|l|}{$\mathrm{LT}$} & \multicolumn{2}{|l|}{$\overline{\mathrm{SLU}}$} & & \multirow{2}{*}{$\begin{array}{l}\text { Rank } \\
\text { Order }\end{array}$} & \multirow[t]{2}{*}{ Decision } \\
\hline & $\mathrm{X}$ & St.D & $\mathrm{X}$ & St. D & Set & & \\
\hline Library use is taught in school & 2.41 & 0.40 & 2.39 & 0.40 & 2.40 & & Disagreed \\
\hline The course is clear to one & 2.41 & 0.40 & 2.49 & 0.41 & 2.45 & & Disagreed \\
\hline $\begin{array}{l}\text { I can effectively use the library from } \\
\text { teaching I got from GES } 100\end{array}$ & 2.47 & 0.40 & 2.47 & 0.40 & 2.45 & & Disagreed \\
\hline $\begin{array}{l}\text { It teaches library users the organization of } \\
\text { library materials }\end{array}$ & 2. 49 & 0.49 & 2.49 & 0.49 & 2.49 & & Disagreed \\
\hline Aggregate Mean Score & 2.45 & & 2.44 & & 2.45 & & Disagreed \\
\hline
\end{tabular}

Key: Library Tour(LT) Students Library Utilization (STU)

Table 2 describes the mean scores and standard deviation of the course library use course and students' library. The respondents agreed on all the items in the table with high mean scores greater than the mean 
criterion of 2.50 following the rank order from $1^{\text {st }}$ to $4^{\text {th }}$. The aggregate mean score of 2.45 shows that the ways library use course (GES 100) affects students' library utilization in the Faculty of Humanities in University of Port Harcourt include: the course GES 100 is taught but students are not graded on practical usage of the library, the course is not clear to student no effective use of library by students, teaches library users the organization of library materials without commitment of students which affects students library utilization.

Research Question 3: How does library orientation enhance students' library utilization?

Table 3: Mean scores of respondents on the impact of library orientation on students' library utilization.

Questionnaire Item

It made me to be aware of library $2.47 \quad 0.40$ resources to use

It has enable me to build a reading culture $\quad 2.82 \quad 0.54$

It has enable me to retrieve needed 2.590 .46 information from the library

It has inspired me to always use the library Aggregate mean scores

\begin{tabular}{lllll} 
SLU & & Mean & Rank & Decision \\
$\mathrm{X}$ & St. D & Set & $\begin{array}{l}\text { Order } \\
4^{\text {th }}\end{array}$ & Disagreed \\
2.48 & 0.40 & 2.48 & & \\
3.29 & 0.62 & 3.06 & $1^{\text {st }}$ & \\
2.5 & 0.43 & 2.55 & $3^{\text {rd }}$ & \\
2.59 & 0.46 & 2.75 & $2^{\text {nd }}$ & \\
2.72 & 0.48 & 2.89 & & Agreed \\
\hline
\end{tabular}

Key: Library Tour(LT) Students Library Utilization (STU)

Data on table 3 describes the mean scores and standard deviation of library orientation (LO) and students' library utilization (SLU). The respondents agreed on items 10-12 in the table with high mean scores greater than the mean criterion of 2.50 following the rank order from $1^{\text {st }}$ to $3^{\text {rd }}$ and disagreed on item 9 with low mean score. The aggregate mean score of 2.89 shows that the ways library orientation enhances students' library utilization in the Faculty of Humanities in University of Port Harcourt includes: unawareness of library resources for use by students, it builds a reading culture in students, it helps the students to retrieve needed information from the library, it always inspires students to use the library which has tremendously enhanced students' library utilization geared towards achieving coveted educational objectives.

\section{Test of Hypotheses}

Ho1: There is no significant difference between library tour and students' library utilization

\begin{tabular}{lllllll}
\hline Variable under study & X & St.D & df & $z$-cal & z-crit & decision \\
Library tour & 2.96 & 0.48 & 168 & 1.98 & \pm 1.96 & Significant
\end{tabular}

Students' library utilization $\quad 2.01 \quad 0.47$

In table 4 , the $z$-calculated value 1.98 is greater than the $z$-critical value \pm 1.96 at 0.05 level of significance. This explain that the null hypothesis is rejected sowing that there is a significant difference between library tour and students' library utilization in the Faculty of Humanities in University of Port Harcourt.

Ho2: There is no significant difference between library use course (GES 100) and students' library utilization

Table 5: Summary of z-test on the variables under study.

Variable under study

Library use course (GES 100) $\quad 2.47 \quad 0.48 \quad 168$

z $z$-cal

z-cal z-crit

$\pm 1.96$

decision

Students' library utilization $\quad 2.17 \quad 0.38$

Table 5 shows that the $z$-calculated value 1.01 is less than the $z$-critical value \pm 1.96 at 0.05 level of significance. This explains that the null hypothesis is accepted showing that there is no significant difference between library use course (GES 100) and students' library utilization in the Faculty of Humanities in University of Port Harcourt.

Ho3: There is significant difference between library orientation and students' library utilization Table 6: Summary of z-test on the variable under study

\begin{tabular}{lllllll}
\hline Variable under study & X & St.D & df & $z$-cal & $z$-crit & decision \\
Library orientation & 2.89 & 0.49 & 168 & 2.20 & \pm 1.96 & Significant \\
Students' library utilization & 2.01 & 0.48 & & & & \\
\hline
\end{tabular}

Table 6 shows that the $z$-calculated value 2.20 is greater than the $z$-critical value \pm 1.96 at 0.05 level of significance. This indicates that the null hypothesis is rejected showing that there is a significant difference between library orientation and students' library utilization in the Faculty of Humanities in University of Port Harcourt. 
Discussion of findings

How does library tour enhance students' library utilization in the Faculty of Humanities, University of Port Harcourt?

The findings revealed that, ways library tour enhances students' library utilization in the Faculty of Humanities in University of Port Harcourt includes: it builds positive image about the university library and its services, it is relevant to research, tour is not boring to the user, a tour is made known to users, which has tremendously enhanced effective teaching and learning to take place at the level of the students' library utilization geared towards the attainment of optional educational goals. The test of hypothesis one shows that the result was significant indicating that the null hypothesis was rejected. In line with the findings, Ogunmodede and Emeahara (2015) posits that students' library tour acquaint them with the available library resources and facilities capable of aiding their understanding on how well and how best to utilize these resources for desired academic performance. The scholars maintained that students' familiarity with reference resources helps in the retrieval of relevant electronic resources and its utilization for the purpose of achieving coveted educational goals aimed at learners' behavioural change. Esse ad Ugwumba (2014) endorsed that the quality of students' library tour is a function of quality students library utilization which actualize the sustainable optional satisfaction. The effectiveness of any library is measured by the use of its resources and services, but these resources and services cannot be appreciated if students' library tour is not given the priority it deserves. By touring, students are abreast with facilities and resources on ground which positions them for academic exploits.

How does library Use (GES 100) affects students' library utilization in the Faculty of Humanities, University of Port Harcourt.

The findings affirms that the ways library use course (GES 100) affects students' library utilization in the Faculty of Humanities, University of Port Harcourt include: the course "GES 100" is taught is not clear to the students because it is combined with other subjects, no effective use of library by students, the course teaches library users the organization of library materials without commitment of students, which affects students' library utilization. The test of hypothesis two reveals that the result was not significant indicting that the null hypothesis was accepted. This findings synchronizes with the findings of Maduako (2013) who argued that the function of a library's user education/instruction programme may to some extent determine the dimension of library use, particularly where information handling and retrieval skills have been impacted to users. This means that if the information handling and retrieval skills are not well impacted to the users, the instruction programme (in this case-GES 100) may be frustrated and intended predetermined objectives of the course may equally not be achieved. The growth of inter-disciplinary course in higher institution requires that the students be trained and able to make efficient use of wide range of resources available in the library. This is not the case with GES 100 where the course is taught but students are given examination only and not practical usage of library to assess if they really understand how to make use of library. This no doubt, affect the effective teaching and learning geared towards changing the behavioural pattern of the learner. Esse and Ugwumba (2014) affirms that there cannot be a connection between user and materials or tools without proper education given to users who may not have prior knowledge or idea on the use of such materials this is indispensable instrument for effective use of library resources.

How does library orientation enhance students' library utilization in Faculty of Humanities, University of Port Harcourt.

The findings revealed that the ways library orientation enhances students' library utilization in Faculty of Humanities, University of Port Harcourt include: unawareness of library resources for use by students it builds reading culture in students, it helps the students to retrieve needed information from the library, it always inspires students to use the library which has tremendously enhanced students' library utilization geared towards the attainment of coveted educational goals. The test of hypothesis three shows that the result was significant indicating that the null hypothesis was rejected. In line with the findings, Uwakwe et al(2016) contends that the fundamental objective of users' orientation is to expose, acquaint and inculcate in the clients, the basic knowledge of understanding and skills which are necessary for effective and efficient use of the library resources and services. This is why Bem-bura (2015) maintained that users' library orientation programme cannot afford to ignore the importance of carrying out the programme so as to equip and acquaint the learner to appreciate the available needed e-resources and facilities for optimall utilization aimed at the achievement of predetermined educational objectives. Kiilu and Otike (2016) findings reveals that library orientation is necessary for effective use of library that facilitates information gathering skill, knowledge and utilization of library resources and facilities.

Conclusion

Librarians should be very proactive when it comes to library user education in order to promote library usage. 
Librarians should also create a platform for students library hour in order to acquaint them with modern happenings in the e-library. Also teaching GES 100 once in a session is not enough to make students to use the library. In order to arouse the quest for knowledge and make students cultivate reading habit and sourcing for information independently. Library user education programmes should be done every semester.

\section{Recommendation}

1. Librarians, should ensure that GES 100 course is not only assessed through examination but ensure that the students use the library so as to effectively assess the performance of their day to day dealing.s with the library for the attainment of desired academic excellence.

2. It is vital for librarians to ensure that library orientation is done for both old users and fresh students in order to promote library accessibility and usage.

3. There should be a conducive environment for teaching GES 100 course use of library in order to increase the impact and also the lecturer's should be adequately motivated.

4. Librarians should create an hour for library Tour once in every month ,sssssssssssss

\section{Implication of the Study}

This study will improve students' utilization of library and its resources. It will enable students not to depend on library staff to locate information sources but will rather do so independently because of the user education program. Thereby making them become independent life-long learners and becoming useful to themselves and the society at large.

\section{References}

Asu, M.K, Cummings, R.G and Wang, S.W. (2014) Business students and perception of university library service quality and satisfaction-contemporary issues in education Research 7(2).

Bembura, M.D. (2015) Students perception of library orientation programme in Benue State University, Makurdi. International Journal of Innovative Research and Development, 43, P. 78- Retrieved from http://www.ijird.com/index.php/article/view/2019.

Esse, O and Ugwumba, C. (2014) Effective library instruction on the satisfaction with the use of library and its services. A case study of undergraduate on five universities in southern part of Nigeria, European Scientific Journals, 10(3).

Joseph, M. (2005) Encouraging user education in Nigerian Academic Libraries towards effectiveness. Journal of Research in Education $2(1 \& 2)$ 24-30.

Kanazawa, M.M. (2016) information literacy education in Japanese libraries for - life long learning. Hauppage, NV: Nova Science Publications Inc.

Kiku, P.W. and otike, J. (2016) Non-use of academic library services, a literature review. Journal of Library Science, 5,1,7B

LI, X.K (2013) Library user study introduction. National Library Publication Inc. S

Maduako, P.M. (2013) User education and library use of College of Education Abia and Imo State Library. Library philosophy and practice. Retrieved from http://digital/commons/un/limphil/pract.

Obasuyi, L.I and Idiodi, E.O. (2015) Influence of library value on university education students perception survey, advances in Social Science Research Journal, 2(7), 120 - 136.

Oni, O.O. A survey of catalogue patronage for information retrieval by undergraduate. A case study of FUTA library fountain of knowledge: Journal of Library and Information Science 2(1), 57.

Qianxlu Liu, Patrick, Lo and Itsumura Hiroshi. Measuring the importance of library user education. A comparative study between Fudhan University and the National Taiwan Normal University journal of Academic Librarianship, 42(6) P. 44-54.

Uwakwe, S.B. Onyeneke and Njoku, I.N. (2016). Effect of libray user education on students usr of library,ssssss. Imo State University, Owerri Nigeria. Journal of Information and Knowledge Management. 7, (1) :70-85. 